\title{
Editorial: charting the future of hepatocellular carcinoma publications
}

This article was published in the following Dove Press journal: Journal of Hepatocellular Carcinoma

\author{
Ahmed Omar Kaseb \\ Department of Gastrointestinal \\ Medical Oncology, The University of \\ Texas MD Anderson Cancer Center, \\ TX, USA
}

Journal of Hepatocellular Carcinoma (JHC) is a peer-reviewed, comprehensive, multidisciplinary, international journal for publication of original, review, editorial, and commentary articles in addition to expert consensus statements and reports in all clinical and research aspects of hepatocellular carcinoma (HCC). JHC is indexed in PubMed and PubMed Central (J Hepatocell Carcinoma), and in the Emerging Sources Citation Index.

The overarching objective of the JHC is to provide a better understanding of risk factors, pathogenesis, and clinical management of HCC and to advance collaboration and dialogue between researchers and clinicians in academic, private practice, and industry settings. Since its inception, papers submitted to JHC have represented a wide range of articles, including clinical trials, ${ }^{1}$ review articles in both research and clinical topics, ${ }^{2-4}$ editorials, commentaries, case series, and an important expert consensus statement on liver imaging. ${ }^{5}$

Our journal strategy going forward will be encouraging and incentivizing publications related to multidisciplinary research and clinical topics that could potentially have a significant impact on HCC management. Specifically, of high interest are articles related to understanding and managing this peculiar cancer, which usually involves a two-disease state: HCC and underlying chronic liver disease. Additionally, to date, significant progress has been achieved in the area of comprehensive multidisciplinary and individualized HCC screening and treatment algorithms. However, certain advanced modalities for HCC screening and treatment are relatively expensive, especially in certain developing countries, where local resources and health care budget are limited.

Therefore, in response to a call from the HCC scientific community, we are launching a new era in JHC that will address the global differences in HCC risk factors and management strategies. JHC is launching a Call for Papers: we are seeking to publish multidisciplinary clinical and translational studies, in addition to cost-effective screening and treatment strategies and consensus statements including those which take into account available local resources. Notably, the rapidly evolving field of immunotherapy as a treatment for HCC has shown substantial promise. ${ }^{6}$ Therefore, of major interest to our journal and its readers are basic and clinical research reports in the field of HCC immunotherapy. The full Call for Papers can be found here: https://www. dovepress.com/journal-of-hepatocellular-carcinoma-archive148.
Correspondence: Ahmed Omar Kaseb Department of Gastrointestinal Medical Oncology, The University of Texas MD Anderson Cancer Center, 1515 Holcombe Blvd., Unit 426, Houston, TX 77030, USA

$\mathrm{Tel}+\mathrm{I} 7137922828$

Fax + I $7|3563054|$

Email akaseb@mdanderson.org
Journal of Hepatocellular Carcinoma 20I8:5 5I-54

(c) (1) (8) ( 2018 kaseb. This work is published and licensed by Dove Medical Press Limited. The full terms of this license are available at https://www.dorepress.com/terms.

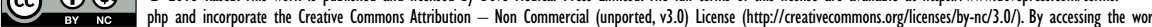
you hereby accept the Terms. Non-commercial uses of the work are permitted without any further permission from Dove Medical Press Limited, provided the work is properly attributed. For permission for commercial use of this work, please see paragraphs 4.2 and 5 of our Terms (httpss//www.dovepress.com/terms.php). 
Finally, we are proud to welcome our newly expanded Editorial Board (please see Supplementary material for the complete list), which now includes a larger global representation by established HCC expert clinicians and academicians from all continents. On behalf of JHC Editorial Board, we herein invite you to submit your manuscripts, suggestions, and interesting ideas to improve our journal performance and truly represent global HCC clinical and research topics to improve the dismal outcome of our HCC patients.

\section{Disclosure}

The author reports no conflicts of interest in this work.

\section{References}

1. Salama H, Ahmad H, Elchagea I, et al. Ambovex ${ }^{\circledR}$ as a novel immunological modulator drug for the treatment of hepatocellular carcinoma (HCC) in the liver: a Phase II clinical trial. J Hepatocell Carcinoma. 2015;2:79-89.

2. Balogh J, Victor D, Asham EH, et al. Hepatocellular carcinoma: a review. $J$ Hepatocell Carcinoma. 2016;3:41-53.

3. Shi J, Keller JM, Zhang J, Keller ET. A review on the diagnosis and treatment of hepatocellular carcinoma with a focus on the role of Wnts and the dickkopf family of Wnt inhibitors. J Hepatocell Carcinoma. 2014;1:1-7.

4. Kew M. Hepatocellular carcinoma: epidemiology and risk factors. J Hepatocell Carcinoma. 2014;1:115-125.

5. Elsayes KM, Kielar AZ, Agrons MM, et al. Liver imaging reporting and data system: an expert consensus statement. $J$ Hepatocell Carcinoma. 2017;4:29-39.

6. El-Khoueiry AB, Sangro B, Yau T, et al. Nivolumab in patients with advanced hepatocellular carcinoma (CheckMate 040): an open-label, non-comparative, phase $1 / 2$ dose escalation and expansion trial. Lancet. 2017;389(10088):2492-2502. 


\section{Supplementary material}

Journal of Hepatocellular Carcinoma Editorial Board December 2017

Editor-in-Chief: Dr Ahmed Kaseb, Associate Professor and Program Director of Hepatocellular Carcinoma, Department of Gastrointestinal Medical Oncology, University of Texas MD Anderson Cancer Center, Houston, TX, USA

Associate Editor-in-Chief: Prof Junji Furuse, Department of Internal Medicine, Medical Oncology, Kyorin University School of Medicine, Japan

Associate Editor-in-Chief: Dr Ravi Murthy, Professor of Interventional Radiology, Department of Interventional Radiology, University of Texas MD Anderson Cancer Center, Houston, TX, USA

Associate Editor-in-Chief: Prof Xin Wang, Laboratory of Human Carcinogenesis, National Cancer Institute, USA

\section{Editorial Board members:}

Prof Ashraf Abdelaziz, Professor of Hepatology and Endemic Medicine and Director of Multidisciplinary HCC Clinic, Cairo University, Egypt

Prof Stephen Beebe, Professor, Frank Reidy Research Center for Bioelectrics, Old Dominion University, Norfolk, VA, USA

Prof Srikanta Dash, Director of Hepatitis Research Laboratory, Department of Pathology and Laboratory Medicine, Gastroenterology and Hepatology, Tulane University Health Sciences Center, New Orleans, LA, USA

Dr Aldo Dettino, Professor in Clinical Oncology and Translational Research, Department of Clinical Oncology, A. C. Camargo Cancer Center, Sao Paulo-SP, Brazil

Dr Dan Duda, Director of Translational Research in GI Radiation Oncology; Investigator, Edwin L. Steele Laboratories for Tumor Biology, Department of Radiation Oncology, Massachusetts General Hospital; Associate Professor of Tumor Biology, Harvard Medical School, Charlestown, MA, USA

Prof Khaled Elsayes, Professor of Diagnostic Radiology, University of Texas MD Anderson Cancer Center and the Medical School of University Texas in Houston, Houston, TX, USA

Prof David Gerber, Professor and Division Chief, Division of Transplantation, Department of Surgery, University of North Carolina School of Medicine, Chapel Hill, NC, USA
Prof Manal Hassan, Associate Professor, Department of GI Medical Oncology, University of Texas MD Anderson Cancer Center, Houston, TX, USA

Dr Heping Hu, Director and Professor, Department of Heptobiliary Diseases, Eastern Hepatobiliary Hospital, Shanghai, People's Republic of China

Dr Do Young Kim, Associate Professor in Hepatology, Department of Internal Medicine, Yonsei University College of Medicine, Seoul, Korea

Prof Kyung Sik Kim, Severance Hospital, Department of Surgery and Yonsei University, College of Medicine, Seoul, Korea

Prof Philippe Merle, Professor of Hepato-Gastroenterology and Digestive Oncology, Leader of research team "Hepatocarcinogenesis and viral infections", UMR INSERM 1052 - CNRS 5286, Centre of Research in Cancerology, Lyon University and Croix-Rousse Hospital, Lyon, France

Dr Ganesh Nagarajan, Consultant Surgeon Hepatobiliary Pancreatic, GI oncology \& Liver Transplant, P D Hinduja Hospital, Mumbai, India

Prof Irene Oi-Lin Ng, Loke Yew Professor and Chair Professor in Pathology, Director of State Key Laboratory for Liver Research, The University of Hong Kong, Hong Kong

Prof Tushar Patel, Professor of Medicine, Mayo Clinic College of Medicine, Rochester, MN, USA

Prof Rodolfo Sacco, Gastroenterology and Hepatology Unit of Cisanello Pisa University Hospital, Pisa, Italy

Prof Toshihito Seki, Professor and Director, Division of Gastroenterology and Hepatology, Kansai Medical University Medical Center, Osaka, Japan

Prof Mohamed Kamal Shaker, Professor of Tropical Medicine, Faculty of Medicine, Ain Shams University, Cairo, Egypt

Prof Feng Shen, Eastern Hepatobiliary Surgery Hospital, Second Military Medical University, Shanghai, People's Republic of China

Prof Ming Shi, Department of Hepatobiliary Oncology, Cancer Center, Sun Yat-sen University, People's Republic of China

Prof Dr Oliver Stoeltzing, Head Doctor, Zentrum für Allgemein- und Viszeralchirurgie Riesa-Meißen, Elblandkliniken, Meißen, Germany

Prof Hua Tang, Professor of Molecular Biology \& Microbiology, School of Basic Medical Sciences, Tianjin Medical University, People's Republic of China 
Dr Harrys Torres, Associate Professor of Medicine; Founding Director of Hepatitis C Clinic; Medical Director of Internal Medicine Center, Department of Infectious Diseases, Infection Control and Employee Health; Adjunct Associate Professor, Department of Gastroenterology, Hepatology and Nutrition, The University of Texas MD Anderson Cancer Center, Houston, TX, USA

Prof Dr Joerg Trojan, Professor of Medicine, Gastrointestinal Oncology, Goethe-University Medical Center, Frankfurt, Germany
Prof Dr Toshifumi Wakai, Professor and Chairman, Division of Digestive and General Surgery, Niigata University Graduate School of Medical and Dental Sciences, Niigata, Japan

Prof Jia-Sheng Wang, Professor and Head, Department of Environmental Health Science, College of Public Health, The University of Georgia, Athens, GA, USA

Prof Chia-Jui Weng, Department of Living Services Industry, Tainan University of Technology, Taiwan

Dove Medical Press encourages responsible, free and frank academic debate. The content of the Journal of Hepatocellular Carcinoma 'Editorial' section does not necessarily represent the views of Dove Medical Press, its officers, agents, employees, related entities or the Journal of Hepatocellular Carcinoma editors. While all reasonable steps have been taken to confirm the content of each Editorial, Dove Medical Press accepts no liability in respect of the content of any Editorial, nor is it responsible for the content and accuracy of any Editorial.

\section{Publish your work in this journal}

The Journal of Hepatocellular Carcinoma is an international, peerreviewed, open access journal that offers a platform for the dissemination and study of clinical, translational and basic research findings in this rapidly developing field. Development in areas including, but not limited to, epidemiology, vaccination, hepatitis therapy, pathology and molecular tumor classification and prognostication are all considered for publication. The manuscript management system is completely online and includes a very quick and fair peer-review system, which is all easy to use. Visit http://www.dovepress.com/testimonials.php to read real quotes from published authors.

Submit your manuscript here: https://www.dovepress.com/journal-of-hepatocellular-carcinoma-journal 